\title{
HAEMAGGLUTINATION BY THE TRIC GROUP OF CHLAMYDIA
}

\author{
Memory P. F. Elvin-Lewis* and J. W. Czekalowski \\ Division of Virology, Department of Bacteriology, \\ School of Medicine, Leeds
}

Plate V

Psit TA Cosis and other related members of the Chlamydia form agglutinins for murine erythrocytes during growth in fertile eggs (Hilleman, Haig and Helmold, 1951; Gogolak, 1954; Gogolak and Ross, 1955). This paper describes similar haemagglutinins associated with the replication of the TRIC sub-group of agents (see also Elvin-Lewis, 1965).

\section{MATERIALS AND METHODS}

TRIC strains. Four strains of trachoma agent, G1(TRIC/ /WAG/MRC-1/OT), T'ang (TRIC/ /China/Peking-2/OTf), TW 29 (TRIC/ / TAIWAN/NAMRU 2-3/OT) and TW 97 (TRIC/ / TAIWAN/NAMRU 2-97/OT), and one of inclusion conjunctivitis, LB1 (TRIC//GB/ MRC-1/G), were studied. The Taiwan trachoma strains were kindly provided by Dr R. L. Woolridge, US Naval Medical Research Unit NAMRU-2, Taipei, Taiwan, and the others by Dr L. H. Collier, Lister Institute of Preventive Medicine, London.

Inocula were prepared from normal or heavily infected yolk-sacs, allantoic fluids and chorio-allantoic membranes. The diluents used were phosphate-buffered saline (PBS) (Dulbecco and Vogt, 1954), sucrose potassium glutamate (SPG) (Bovarnick, Miller and Snyder, 1950) or modified sucrose potassium glutamate (MSPG) (Wang and Grayston, 1964), containing $1000 \mu \mathrm{g}$ streptomycin per ml. Crude homogenates were prepared by vigorously shaking 10-20 per cent. (w/v) suspensions of yolk-sacs in diluent with glass beads for $5 \mathrm{~min}$.; floating yolk and cellular debris were removed by low-speed centrifugation. Partially purified TRIC agent particles were prepared from chorio-allantoic membranes by lightly shaking 5 per cent. membrane suspensions $(\mathrm{w} / \mathrm{v})$ in sterile 2 per cent. ammonium acetate for $5 \mathrm{~min}$. (Litwin et al., 1961). The extracted particles were concentrated by differential centrifugation ( $2000 \mathrm{~g}$ for $10 \mathrm{~min}$. followed by $8000-12,000 \mathrm{~g}$ for $45 \mathrm{~min}$.) and finally suspended in a small amount of diluent. TRIC agent particles in allantoic fluids were similarly concentrated by differential centrifugation.

On some occasions TRIC particles were washed three times with MacIlvaine-saline buffer (Hare, McClelland and Morgan, 1942) before examination for haemagglutinating activity.

Infectivity tests. Serial dilutions of TRIC agent preparations were inoculated into the yolk-sac of 6-8-day-old fertile hen's eggs in 0.5-ml amounts. Yolk-sacs were harvested from embryos dying after $72 \mathrm{hr}$ and also from those surviving 7-10 days after inoculation. Impression smears were made and stained with May Grünwald-Giemsa, according to the procedure used at the Lister Institute of Preventive Medicine. Air-dried smears were fixed for $10 \mathrm{~min}$. in 95 per cent. methanol or ethanol, stained for $30-60 \mathrm{~min}$. in a mixture of 10 per cent. Giemsa and 5 per cent. May Grünwald (G. T. Gurr, London) freshly diluted in phosphate buffer $p \mathrm{H} \mathrm{6.8,} \mathrm{decolorised} \mathrm{for} 5 \mathrm{~s}$ in 95 per cent. ethanol and finally differentiated

Received 18 Feb. 1970; accepted 20 July 1970.

* Present address: Department of Microbiology, School of Dentistry, Washington University, St Louis, Mo. 63110, USA.

J. MED, MICROBIOL.-VOL. 4 (1971) 
for $10 \mathrm{~min}$. in phosphate buffer $p \mathrm{H} \mathrm{6.8.} \mathrm{When} \mathrm{overnight} \mathrm{staining} \mathrm{was} \mathrm{used} \mathrm{the} \mathrm{stain} \mathrm{mix-}$ ture consisted of 0.5 per cent. May Grünwald and 1 per cent. Giemsa in phosphate buffer. Elementary bodies stained light blue to pink and initial bodies stained dark blue. Staining of glycogen elements was carried out according to the method of Gilkes, Smith and Sowa (1958). Chorio-allantoic membrane cells were examined by similar techniques.

Sterility tests. Pieces of yolk-sac or chorio-allantoic membrane or drops of allantoic fluid were placed in thioglycollate broth and also smeared on fresh and heated blood agar plates, which were incubated aerobically at $37^{\circ} \mathrm{C}$. Broth and plates were examined daily for 7 days for evidence of bacterial growth.

Haemagglutinin preparation. Inocula were injected, in $0 \cdot 25-1-\mathrm{ml}$ volumes, into the allantoic cavity of 7-9-day-old embryonated eggs; control eggs were given diluent only. After incubation for $3-6$ days at $35^{\circ} \mathrm{C}$, the eggs were chilled at $4^{\circ} \mathrm{C}$ and the allantoic fluids harvested. These were tested individually for sterility and haemagglutinating activity, and stored either separately or pooled at $-40^{\circ} \mathrm{C}$ or $-70^{\circ} \mathrm{C}$. When TRIC agent particles were to be used in haemagglutination tests they were separated from the allantoic fluids by centrifugation at $8000 \mathrm{~g}$ for $1 \mathrm{hr}$ at $4^{\circ} \mathrm{C}$ before being stored. The haemagglutinin in allantoic fluid could be concentrated as much as ten-fold by thawing frozen material at $4^{\circ} \mathrm{C}$, centrifuging at $12,000 \mathrm{~g}$ for $1 \mathrm{hr}$ at $4^{\circ} \mathrm{C}$ and resuspending the sediment in Macllvaine-saline buffer $p \mathrm{H} \mathrm{7.0} \mathrm{(Hare} \mathrm{et} \mathrm{al.;}$ Gogolak). Haemagglutinins in chorio-allantoic membranes and yolk-sacs were extracted with 2 per cent. ammonium acetate (Litwin et al.). The agent particles in the extract were deposited by high-speed centrifugation and resuspended in a small amount of Macllvainesaline. The supernatant was kept at room temperature for $3 \mathrm{hr}$ to allow the ammonium acetate to evaporate. The preparations were then tested for haemagglutinins immediately or stored at $-40^{\circ} \mathrm{C}$. Control uninfected chorio-allantoic membranes or yolk-sacs were treated similarly.

Erythrocyte suspensions. Blood was collected into equal volumes of Alsever's solution (Muschel and Lowe, 1955) from human volunteers, white mice, Wistar-Sheffield rats, guineapigs, sheep, cockerels or frogs (Rana pipiens). The erythrocytes were washed three times with 0.85 per cent. saline and used as a 1 per cent. suspension in MacIlvaine-saline. Freshly prepared erythrocytes were used in all tests, except those in which the effect of overnight storage at $4^{\circ} \mathrm{C}$ was examined. Different batches of mouse and rat erythrocytes varied in their sensitivity to agglutination; suitable cells were therefore selected by preliminary testing.

Haemagglutination tests were carried out in Perspex haemagglutination trays. Serial two-fold dilutions of the test material were prepared in $0.5-\mathrm{ml}$ volumes in MacIlvaine-saline. To each dilution was added $0.25 \mathrm{ml}$ of 1 per cent. red cells. The trays were gently agitated and kept at room temperature for 3-16 hr before reading the settling pattern of the erythrocytes (Stavitsky, 1954); obvious granules of agglutinated erythrocytes indicated a positive result, a button that on mixing produced a homogeneous cell suspension, a negative result. Inconclusive readings could often be resolved by stirring the test suspensions and allowing them to resettle. Controls consisting of erythrocytes suspended in diluent, as well as in uninfected allantoic fluid or extracts prepared from uninfected tissues, were included in all tests.

\section{RESULTS}

\section{Haemagglutinins for mouse erythrocytes in allantoic fluids}

Five days after infection with yolk-sac-adapted strains of Taiwan 29 and Taiwan 97, few eggs showed the presence of agglutinins for mouse erythrocytes in the allantoic fluid; low titred $(1$ in 4$)$ but demonstrable $(3+)$ haemagglutinin activity was present in one out of ten Taiwan 29-infected eggs, and absent from a similar number of eggs infected with Taiwan 97. However, after concentration of the pooled allantoic fluids by the freezing-thawing method definite haemagglutinating activity was demonstrable for both strains. Subsequently, 
HaEmagglutination By TRIC agents

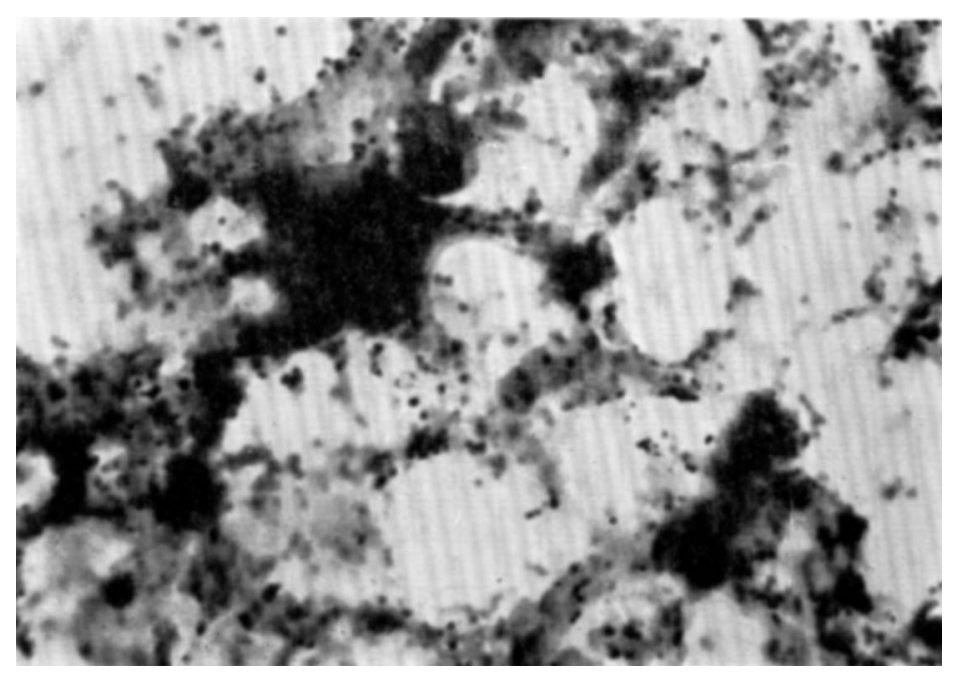

FIG. 1.-Taiwan 29 trachoma strain. Particles deposited by high-speed centrifugation from allantoic fluid of eggs infected via the allantoic cavity. Both sizes of elementary bodies are present, large forms being predominant. May Grünwald-Giemsa. $\times 1000$.

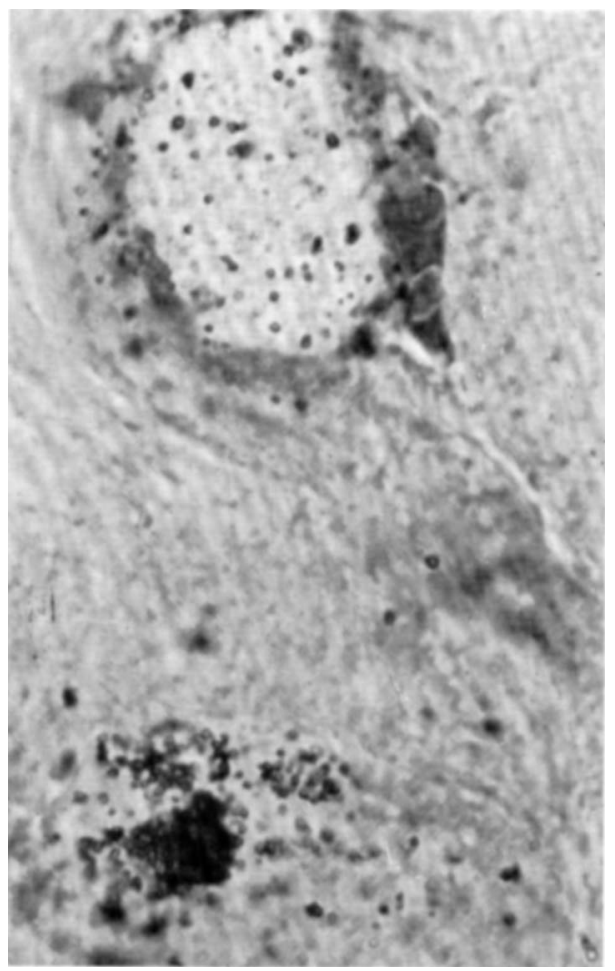

FIG. 2.-Cells of the chorio-allantoic membrane infected with Taiwan 97 trachoma strain. Inclusions contain various sizes of elementary bodies; mature forms are enveloped in Lugolpositive material. Lugol's iodine. $\times 1000$.

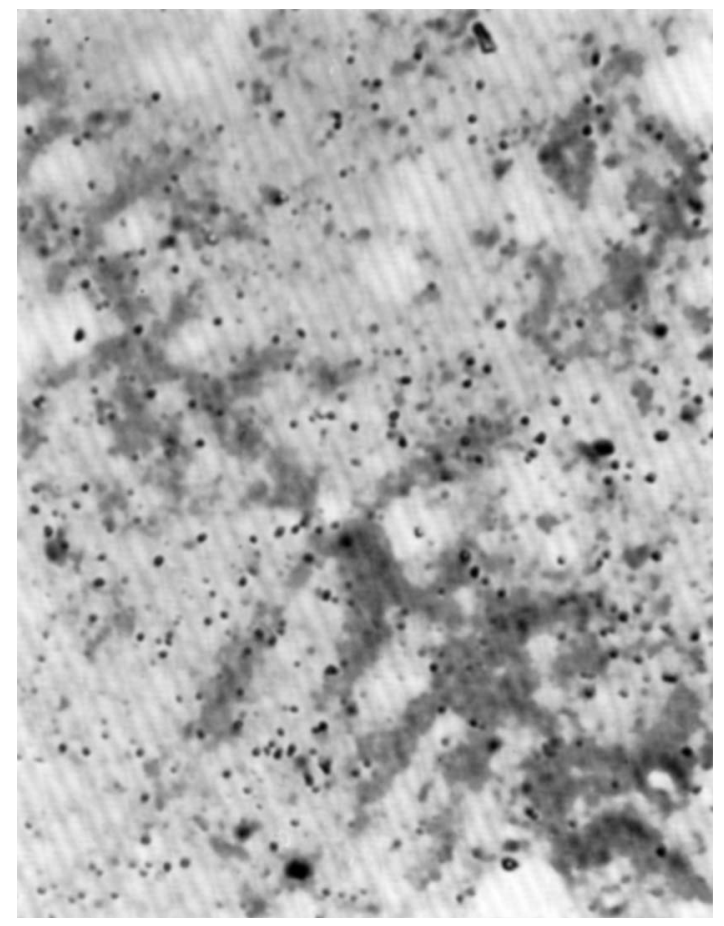

FIG. 3.-Smear prepared from ammonium acetate extract of chorio-allantoic membranes infected with inclusion conjunctivitis agent, strain LB1. Large and small elementary bodies are visible. May GrünwaldGiemsa. $\times 1600$. 
allantoic fluid concentrates were prepared from eggs infected with various TRIC strains, and these were examined for the presence of haemagglutinins immediately and also after storage at $4^{\circ} \mathrm{C}$ for $24 \mathrm{hr}$ and $14 \mathrm{wk}$ (table I). The fresh concentrates all showed marked haemagglutinating activity, but this usually decreased considerably after overnight storage and was very weak or

TABLE I

Effect of storage on TRIC-agent haemagglutinin activity for mouse erythrocytes

\begin{tabular}{|c|c|c|c|c|c|c|c|c|c|c|c|c|}
\hline \multirow{4}{*}{ TRIC agents } & \multicolumn{12}{|c|}{ Haemagglutinin titre* of pooled concentrated chorio-allantoic fluid tested } \\
\hline & \multicolumn{4}{|c|}{ fresh } & \multicolumn{4}{|c|}{ after overnight storage } & \multicolumn{4}{|c|}{ after 14 weeks' storage } \\
\hline & \multicolumn{4}{|c|}{$\begin{array}{l}\text { to give agglutination } \\
\text { of grade }\end{array}$} & \multicolumn{4}{|c|}{$\begin{array}{l}\text { to give agglutination } \\
\text { of grade }\end{array}$} & \multicolumn{4}{|c|}{$\begin{array}{c}\text { to give agglutination } \\
\text { of grade }\end{array}$} \\
\hline & $4 \uparrow$ & 3 & 2 & 1 or $<1$ & 4 & 3 & 2 & 1 or $<1$ & 4 & 3 & 2 & 1 or $<1$ \\
\hline $\begin{array}{l}\text { TW } 29(a) \ddagger \\
\text { TW } 29(b) \ddagger \\
\text { TW } 97(a) \ddagger \\
\text { TW } 97(b) \ddagger \\
\text { Gambia } \\
\text { T'ang } \\
\text { LB1 }\end{array}$ & $\begin{array}{r}2 \\
16 \\
8 \\
8 \\
2 \\
8 \\
8\end{array}$ & $\begin{array}{r}8 \\
32 \\
16 \\
16 \\
8 \\
16 \\
32\end{array}$ & $\begin{array}{r}256 \\
128 \\
128 \\
32 \\
16 \\
128 \\
128\end{array}$ & $\begin{array}{l}256 \\
256 \\
256 \\
256 \\
256 \\
256\end{array}$ & $\begin{array}{c}4 \\
? \S \\
? \S \\
8 \\
32 \\
? \S\end{array}$ & $\begin{array}{l}\dddot{8} \\
\ldots \\
\dddot{16} \\
64 \\
\ldots\end{array}$ & $\begin{array}{c}16 \\
\ldots \\
\ldots \\
32 \\
128 \\
\ldots\end{array}$ & $\begin{array}{r}64 \\
\ldots \\
\ldots \\
64 \\
256 \\
\ldots\end{array}$ & $\begin{array}{l}\ldots \\
\cdots \\
? \S \\
? \| \\
\dddot{32} \\
\cdots\end{array}$ & $\begin{array}{c}2 \\
\ldots \\
\ldots \\
\ldots \\
64 \\
\ldots\end{array}$ & $\begin{array}{r}4 \\
2 \\
\ldots \\
\ldots \\
4 \\
128 \\
4\end{array}$ & $\begin{array}{c}64 \S \\
\ldots \\
\ldots \\
\cdots \\
8 \\
256 \\
8\end{array}$ \\
\hline
\end{tabular}

* When the fluid produces the stated grade of haemagglutination at a dilution of 1 in $x$, the haemagglutinin titre at that grade is recorded as $x$.

$\dagger$ The figures $1-4$ represent an arbitrary scale of increasing degrees of haemagglutination, based on the settling pattern of the red cells.

$\ddagger(a)$ and $(b)$ refer to different experiments.

$\S$ Questionable settling pattern of erythrocytes.

II Agglutination doubtful, probably absent.

absent after $14 \mathrm{wk}$. The T'ang strain was exceptional in showing no loss of haemagglutinating activity, even after 14 wk.

\section{Effect of storage of mouse and rat erythrocytes at $4^{\circ} \mathrm{C}$ on their susceptibility to agglutination}

When freshly prepared T'ang-allantoic fluid concentrates were titrated against mouse erythrocytes that had been stored at $4^{\circ} \mathrm{C}$ overnight, a nonspecific type of agglutination was obtained uniformly throughout the dilution range. This was not observed when the allantoic fluid concentrates were also stored overnight before testing; similar titres were then obtained with both freshly prepared and stored erythrocytes (table II).

Rat red cells were subject to some auto-agglutinability, giving a lacy haemagglutinating pattern, equivalent to a $1+$ to $2+$ reaction, with both infected and control non-infected allantoic concentrates. Only stronger agglutination patterns were, therefore, regarded as significant readings with these cells. 
Unlike mouse red cells, rat cells stored overnight at $4^{\circ} \mathrm{C}$ did not show nonspecific agglutination with freshly prepared T'ang concentrates (table II). Overnight storage did, however, reduce their sensitivity since higher titres were always obtained when stored allantoic fluid concentrates were tested with fresh erythrocytes.

\section{TABLE II}

Effect of storage at $4^{\circ} \mathrm{C}$ on the activity of T'ang strain haemagglutinin and haemolysin for freshly prepared and stored mouse and rat erythrocytes

\begin{tabular}{|c|c|c|c|c|c|c|c|}
\hline \multirow{2}{*}{\multicolumn{2}{|c|}{ Erythrocytes }} & \multirow{3}{*}{$\begin{array}{l}\text { Allantoic } \\
\text { fluids* }\end{array}$} & \multicolumn{5}{|c|}{ Titre of } \\
\hline & & & \multirow{2}{*}{$\begin{array}{l}\text { haemo- } \\
\text { lytic } \\
\text { activity } \dagger\end{array}$} & \multicolumn{4}{|c|}{$\begin{array}{l}\text { haemagglutinating activity } \ddagger \text { to give } \\
\text { agglutination of grade }\end{array}$} \\
\hline Species & Preparation & & & $4 \S$ & 3 & 2 & 1 or $<1$ \\
\hline \multirow[t]{2}{*}{ Mouse } & Freshly prepared & $\begin{array}{l}\mathrm{C} \\
\mathrm{O} \\
\mathrm{S}\end{array}$ & $\begin{array}{r}4 \\
16 \\
\ldots\end{array}$ & $\begin{array}{r}8 \\
32 \\
32\end{array}$ & $\begin{array}{r}16 \\
64 \\
>64\end{array}$ & $\begin{array}{l}128 \\
128 \\
128\end{array}$ & $\begin{array}{l}256 \\
256 \\
256\end{array}$ \\
\hline & $\begin{array}{l}\text { Stored at } 4^{\circ} \mathrm{C} \\
\text { for } 24 \mathrm{hr}\end{array}$ & $\begin{array}{l}\mathrm{C} \\
\mathrm{O}\end{array}$ & $\begin{array}{l}32 \\
16\end{array}$ & $\begin{array}{l}16 \| \\
64\end{array}$ & $\begin{aligned} 32 \| \\
128\end{aligned}$ & $\begin{array}{c}128 \| \\
\ldots\end{array}$ & $\begin{array}{l}256 \| \\
256\end{array}$ \\
\hline \multirow[t]{2}{*}{ Rat } & Freshly prepared & O & 8 & 8 & 16 & 128 & 256 \\
\hline & $\begin{array}{l}\text { Stored at } 4^{\circ} \mathrm{C} \\
\quad \text { for } 24 \mathrm{hr}\end{array}$ & $\mathrm{C}$ & 8 & 8 & $\ldots$ & 32 & 64 \\
\hline
\end{tabular}

* Allantoic fluids: $\mathrm{C}=$ concentrate, freshly prepared; $\mathrm{O}=$ concentrate, stored at $4^{\circ} \mathrm{C}$ for $24 \mathrm{hr} ; \mathrm{S}=$ concentrate, stored at $4^{\circ} \mathrm{C}$ for $14 \mathrm{wk}$.

$\dagger$ When the fluid produces complete or partial haemolysis at a dilution of 1 in $x$, the haemolytic titre is recorded as $x$.

$\ddagger$ When the fluid produces the stated grade of haemagglutination at a dilution of 1 in $y$, the haemagglutinin titre at that grade is recorded as $y$.

$\S$ The figures 1-4 represent an arbitrary scale of increasing haemagglutination, based on the settling pattern of the red cells.

\|| Questionable settling pattern of the erythrocytes, probably due to " auto-agglutination".

Essentially similar results were obtained with allantoic fluid concentrates prepared from eggs infected with Gambia and Taiwan 29 strains.

\section{Haemolytic activity in T'ang concentrates}

Haemolytic activity was originally noticed in fresh allantoic fluid concentrate. The activity was enhanced after overnight storage of the concentrate but disappeared after more prolonged storage. Mouse erythrocytes kept for $24 \mathrm{hr}$ at $4^{\circ} \mathrm{C}$ showed increased sensitivity to freshly prepared but not to stored haemolysin; storage of rat erythrocytes did not affect their sensitivity to either freshly prepared or stored haemolysin (table II).

T'ang strain produced haemolysin irregularly and its induction was unrelated to the concentration, size or lethality of the inoculum. Haemolytic 
activity was removed from allantoic fluid concentrates by centrifugation at 12,000 r.p.m. Individual allantoic fluids were found to contain haemolysin for either mouse or rat erythrocytes, but not for both simultaneously. There was no regular association of haemolytic and haemagglutinating activity, e.g., in one batch of eggs one allantoic fluid contained both haemolysin and haemagglutinin at titres of 2 and 16 respectively, whilst three others were haemolytic only for mouse erythrocytes and without demonstrable haemagglutinating activity.

\section{Cell-associated haemagglutinins}

Chorio-allantoic membranes and yolk-sacs were harvested from eggs infected with Taiwan 29, and chorio-allantoic membranes only from eggs infected with Taiwan 97. These were extracted with ammonium acetate and the extracts centrifuged at high speed as described under Materials and methods. The Taiwan 29 deposits and supernatants were tested against mouse erythrocytes, and those of Taiwan 97 against mouse and rat erythrocytes.

Mouse haemagglutinins were found in the centrifuge deposits of the Taiwan 29 preparations, but not in the corresponding supernatants. Only very weak haemagglutinating activity, for mouse but not rat erythrocytes, was present in the deposit from the Taiwan 97 chorio-allantoic membrane extract.

\section{Attempts to produce chorio-allantoic cavity-adapted strains of TRIC agent}

All the strains used were yolk-sac-adapted and highly infectious (Taiwan 29 and Taiwan 97) or lethal (T'ang and LB1) for the chick embryo.

Allantoic fluids and chorio-allantoic membrane extracts from yolk-sacinfected eggs were separately concentrated and passaged by the allantoic cavity route. Three serial passages were carried out. After each passage impression smears were made from the chorio-allantoic membranes and ordinary smears from their concentrated ammonium acetate extracts. The allantoic fluid was also centrifuged at high speed and smears were prepared from the deposit. The smears were stained with May Grünwald-Giemsa or Lugol's solution and examined under oil immersion for the presence of developmental forms and mature agent particles. Infectivity was confirmed by inoculation of eggs via the yolk-sac.

The attempts at adaptation to the chorio-allantoic cavity failed with all the TRIC strains examined. On the first passage allantoic fluid contained both large and small elementary bodies (fig. 1) and was infectious for eggs by the yolk-sac route. Intact cells of the chorio-allantoic membrane contained both initial bodies and elementary bodies, but Lugol-staining elements were noticed only around the mature forms (fig. 2). The ammonium acetate extracts of the membranes showed similar particles and were also infectious by yolk-sac inoculation (fig. 3). On the second passage the allantoic fluid inoculum infected relatively few cells, which showed the presence of only earlier developmental forms, i.e., initial bodies, staining negatively with Lugol. Similarly, the passage 
of chorio-allantoic membrane extract resulted in the infection of only small numbers of cells which again contained only scanty particles of the early developmental form. The third passage was entirely negative both by morphological examination and infectivity tests.

Passaged material was also examined for the presence of agglutinins for mouse and rat erythrocytes. In the case of Taiwan 97, on the first passage four out of eight allantoic fluids exhibited a weak " haemagglutination-like" reaction with both mouse and rat erythrocytes and two more reacted only with rat cells. After pooling and concentration, however, a definite haemagglutinating activity was observed only with rat erythrocytes, in dilutions up to 1 in 8 . On the other hand, the ammonium acetate extracts of the chorioallantoic membranes reacted only with mouse erythrocytes, giving a weak " haemagglutination-like" pattern at a dilution of 1 in 2 . After the second passage, concentrated allantoic fluids reacted only with rat erythrocytes, but this time showed strong agglutination patterns in dilutions up to 1 in 4 and weaker agglutination up to 1 in 32 . However, no agglutinin was extractable from the chorio-allantoic membrane. In similar experiments with T'ang and LB1, haemagglutinin could not be detected in the allantoic fluids of the first passage, but on the second passage the majority of fluids did react weakly at dilutions between 1 in 4 and 1 in 16 with rat erythrocytes only. With all strains haemagglutinating activity was absent after the third passage.

\section{Agglutination of mouse and rat blood cells by TRIC agent particles}

Partially purified, washed particles of all the TRIC strains were prepared from both allantoic fluids and chorio-allantoic membranes. They were examined for haemagglutinating activity against mouse and rat erythrocytes. All the tests were negative.

\section{Agglutination of erythrocytes of other species}

Sixty allantoic fluids harvested from eggs infected with Taiwan 29, Taiwan 97 or T'ang were tested both individually and also as pooled concentrates against human (group $\mathrm{O}, \mathrm{Rh}$-negative), sheep, cockerel, guinea-pig and frog erythrocytes.

With none of these cells was definite haemagglutination observed. Occasionally, allantoic fluid concentrates, from eggs infected 4 days previously with T'ang strain, produced at a dilution of 1 in 2 a transient, haemagglutination-like pattern with guinea-pig and human erythrocytes. This pattern became noticeable after about $1 \mathrm{hr}$ and disappeared after standing overnight at room temperature. It was difficult to explore this phenomenon further as active pools were obtained only occasionally and the activity disappeared very rapidly on storage.

\section{Factors relating to haemagglutinin production}

In general haemagglutinin formation was irregular, and detectable in only a relatively small proportion of infected eggs (table III). It became apparent, 
HAEMAGGLUTINATION BY TRIC AGENTS

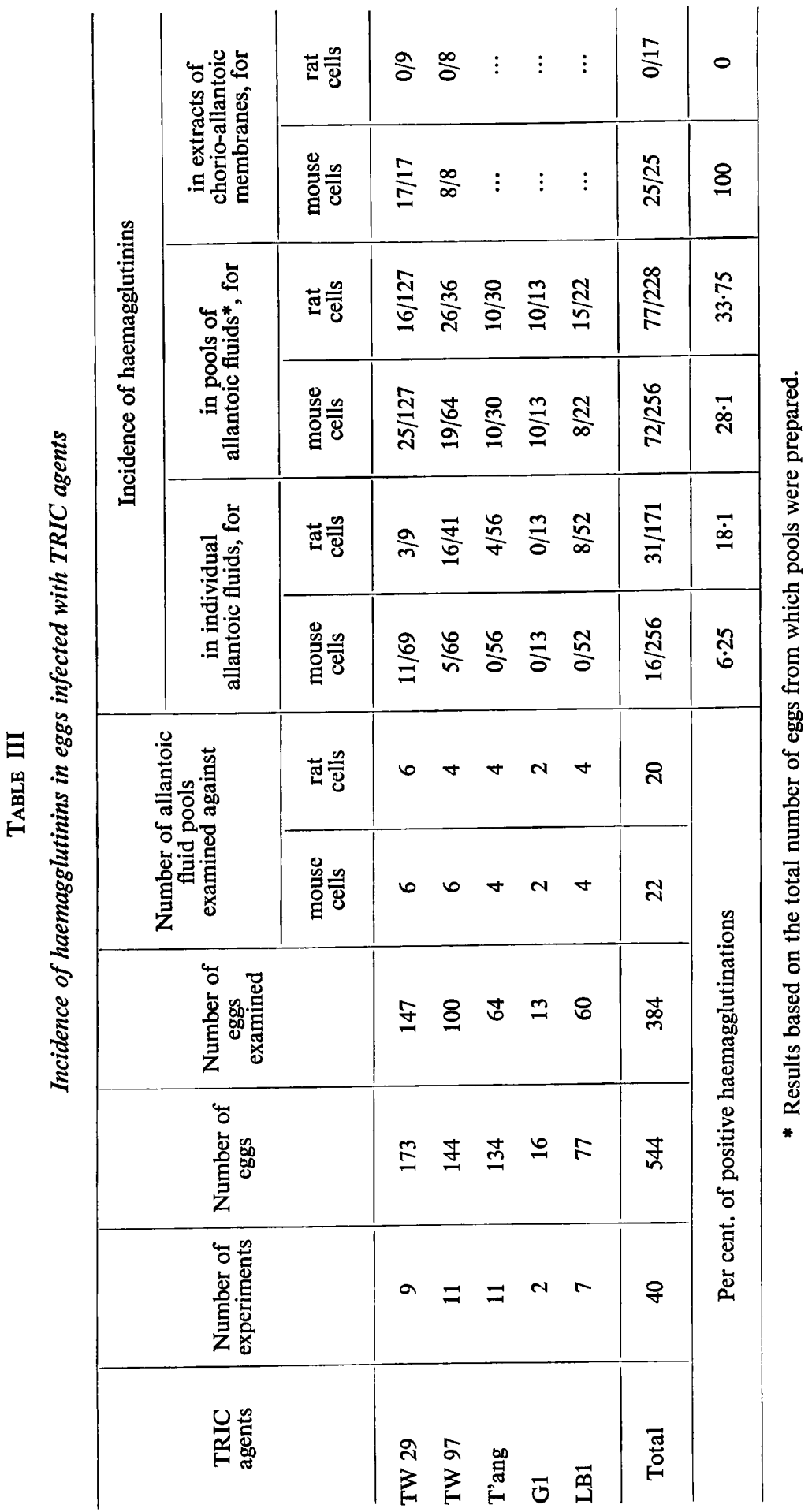


however, that the agglutinins for mouse and rat erythrocytes were not identical. The same batch of material commonly reacted to different titres with the two types of red cell and often only one of the haemagglutinins was detectable. In the majority of tests, with either individual or pooled concentrated allantoic fluids, rat erythrocytes were the more often agglutinated. In contrast, the haemagglutinin associated with infected chorio-allantoic membranes reacted only with mouse erythrocytes (table III).

Table IV suggests that smaller inoculum doses increase the incidence of haemagglutinins in allantoic fluids. This was more evident in the case of the rat cell agglutinin. The latter appeared earlier than the mouse cell agglutinin

TABLE IV

Collated data on all TRIC strains studied illustrating relations between haemagglutinin formation and dilution and volume of inoculum

\begin{tabular}{|c|c|c|c|c|c|}
\hline \multicolumn{2}{|c|}{ Inoculum } & \multicolumn{4}{|c|}{ Incidence of haemagglutinins } \\
\hline \multirow{2}{*}{ Dilution } & \multirow{2}{*}{$\begin{array}{c}\text { Volume } \\
\text { (ml) }\end{array}$} & \multicolumn{2}{|c|}{ individual allantoic fluids } & \multicolumn{2}{|c|}{ pooled allantoic fluids } \\
\hline & & $\begin{array}{l}\text { for mouse } \\
\text { red cells }\end{array}$ & $\begin{array}{l}\text { for rat } \\
\text { red cells }\end{array}$ & $\begin{array}{l}\text { for mouse } \\
\text { red cells }\end{array}$ & $\begin{array}{l}\text { for rat } \\
\text { red cells }\end{array}$ \\
\hline $\begin{array}{l}10^{-1} \\
10^{-1} \\
10^{-2} \\
10^{-2}\end{array}$ & $\begin{array}{l}0.25-0.5 \\
0.75-1.0 \\
0.25-0.5 \\
0.75-1.0\end{array}$ & $\begin{array}{l}9 / 69\left(13 \cdot 0^{*}\right) \\
9 / 76 \quad(11 \cdot 8) \\
2 / 104(1 \cdot 9) \\
5 / 34 \quad(14 \cdot 7)\end{array}$ & $\begin{array}{c}10 / 76\left(13 \cdot 1^{*}\right) \\
10 / 76(13 \cdot 1) \\
0 / 27(0) \\
7 / 14(50 \cdot 0)\end{array}$ & $\begin{array}{l}14 / 71\left(19 \cdot 7^{*}\right) \\
11 / 30(36 \cdot 7) \\
27 / 67(40 \cdot 3) \\
10 / 48(20 \cdot 8)\end{array}$ & $\begin{array}{l}14 / 61(22 \cdot 9 *) \\
18 / 30(60 \cdot 0) \\
27 / 49(55 \cdot 1) \\
18 / 48(37 \cdot 5)\end{array}$ \\
\hline
\end{tabular}

* Percentage positive.

in allantoic fluids, although both reached maximal incidence in eggs by the 5th day, declining rapidly thereafter (table IV). Lethal inocula did not induce the appearance of haemagglutinins.

It was found that even within the same batch of infected eggs some allantoic fluids were active against red cells when undiluted, whilst others were so only after dilution in Macllvaine-saline buffer. Whether the calcium ion reducing factor present in the buffer was relevant to this observation was not further investigated.

\section{Discussion}

Murine haemagglutinins have been described for certain members of the genus Chlamydia, such as the meningopneumonitis agent (Hilleman et al., 1951), the agents of feline and murine pneumonitis (Gogolak, 1954) and the agent of psittacosis (Gogolak and Ross, 1955). These haemagglutinins have certain properties in common. They agglutinate only mouse red cells, they are inhibited by calcium and magnesium ions and inactivated by prolonged storage and they are group-specific in their serological properties. Although they are somewhat erratic in their appearance they tend to reach peak titres in eggs in 
parallel with infectivity. However, they are separable from the infectious particle, and can be concentrated from allantoic fluid by differential centrifugation or by adsorption on to the flocculent precipitate produced by freezing and thawing (Hare et al., 1942). Gogolak and Ross have shown that the haemagglutinin contains phospholipid and nucleoprotein and is probably an integral component of the infectious particle. During replication of the agent the haemagglutinin component is formed in excess and is readily released or extracted from infected cells. The infectious particle itself has no haemagglutinating activity, either before or after sonication.

TABLE V

Collated data on all TRIC strains studied illustrating the increase in haemagglutinin formation in the allantoic cavity with duration of egg infection

\begin{tabular}{|c|c|c|}
\hline \multirow{2}{*}{$\begin{array}{l}\text { Duration of } \\
\text { infection } \\
\text { (days) }\end{array}$} & \multicolumn{2}{|c|}{$\begin{array}{l}\text { Incidence of haemagglutinins in } \\
\text { allantoic fluids for }\end{array}$} \\
\hline & mouse cells & rat cells \\
\hline $\begin{array}{l}3 \\
4 \\
5 \\
6\end{array}$ & $\begin{array}{l}0 / 12\left(0^{*}\right) \\
13 / 129(10) \\
60 / 157(38 \cdot 2) \\
17 / 92(18 \cdot 4)\end{array}$ & $\begin{array}{cc}1 / 12 & \left(8 \cdot 5^{*}\right) \\
27 / 109 & (24 \cdot 7) \\
60 / 127 & (47 \cdot 2) \\
8 / 42 \quad(19)\end{array}$ \\
\hline
\end{tabular}

* Percentage positive.

Haemagglutinins associated with TRIC agents resemble those of the other chlamydia, but they differ in being able to agglutinate both mouse and rat erythrocytes. The T'ang strain, moreover, is exceptional in the stability of its haemagglutinin, as well as in its ability to form a haemolysin also.

The mouse and rat erythrocyte agglutinins appear to be distinct. The growth studies in eggs (tables III, IV and V) showed that the rat red cell agglutinin appeared more quickly and more regularly in the allantoic fluid. On the other hand, extracts of infected chorio-allantoic cells contained mainly the agglutinin for mouse red cells. This was also the case in the adaptation experiments involving allantoic cavity inoculation. These results suggest that the rat cell agglutinin is only loosely attached to the infected cell and is easily released with mature agent particles into the allantoic fluid, whilst the mouse haemagglutinin is more cell-bound. The agglutinins are also formed during abortive infections, and the apparently increased output during the second passage of the adaptation experiment could be due either to the failure of their assembly into mature, non-haemagglutinating particles, or to the disintegration of particles introduced in the inoculum. Our preliminary experiments showed that, as with other chlamydia, the washed, intact, infectious particle of TRIC agents is not haemagglutinating. However, TRIC agents may again be different from other chlamydia in the ease with which they can be disrupted to release active haemagglutinin. Zakay-Rones, Katzenelson and Levy (1968) were able 
to liberate agglutinins for mouse red cells and vaccinia-agglutinable fowl cells from intact trachoma particles by ultrasonication.

The observation that in some allantoic fluids the activity of haemagglutinin associated with TRIC agents appeared only in the presence of calcium-reducing factor suggested that this agglutinin might be sensitive to calcium ions. This would be consistent with findings that calcium and magnesium ions inhibit the activity of haemagglutinin associated with some members of the genus Chlamydia (Hilleman et al.; Gogolak and Ross) and that the magnesium ion has a similar effect on the agglutinin released from trachoma (Zakay-Rones et al.).

Haemagglutinins associated with TRIC agents are not easy to study because of their erratic occurrence, instability and dependence on such factors as inoculum size and susceptibility of erythrocytes. They do provide, however, a valuable tool for the study of the replication of TRIC agents and their interaction with host cells.

\section{SUMMARY}

Several strains of TRIC agent produced agglutinins for mouse and rat erythrocytes during growth in embryonated hens' eggs. The agglutinins appeared irregularly and in a low percentage of inoculated eggs. A small inoculum dose was more likely to give a good yield, and a lethal inoculum failed to produce detectable amounts of haemagglutinin. The haemagglutinins were separable from the infectious particles and, with the exception of those associated with the T'ang strain, were unstable on storage. The agglutinin for rat erythrocytes was more often present in the allantoic fluid whilst the mouse cell agglutinin was more cell-associated. The T'ang strain also produced a haemolysin.

\section{REFERENCES}

Bovarnick, Marianna R., Miller, Judith C., And Snyder, J. C. 1950. The influence of certain salts, amino acids, sugars and proteins on the stability of rickettsiae. J. Bact., 59, 509.

Dulbecco, R., and Vogt, Marguerita 1954. Plaque formation and isolation of pure lines with poliomyelitis viruses. J. Exp. Med., 99, 167.

Elvin-Lewis, Memory P. F. 1965. Studies on the TRIC group of agents. Ph.D. Thesis, Univ. Leeds.

Gilkes, M. J., Smith, C. H., AND Sowa, J. 1958. Staining of the inclusion bodies of trachoma and inclusion conjunctivitis. Br. J. Ophthal., 42, 473.

GogolaK, F. M. 1954. The mouse erythrocyte haemagglutinin of feline pneumonitis virus. J. Infect. Dis., 95, 220.

GogolaK, F. M., AND Ross, M. R. 1955. The properties and chemical nature of the psittacosis virus haemagglutinin. Virology, 1, 474.

Hare, R., McClelland, L., and Morgan, J. 1942. A method for the concentration of influenza virus. Canad. Publ. Hlth J., 33, 325.

Hilleman, M. R., Haig, D. A., And Helmold, R. J. 1951. The indirect complement fixation, haemagglutination and conglutinating complement absorption tests for viruses of the psittacosis-lymphogranuloma venereum group. J. Immun., 66, 115.

Litwin, J., Officer, J. E., Brown, A., AND Moulder, J. W. 1961. A comparative study of the growth cycles of different members of the psittacosis group in different host cells. J. Infect. Dis., 109, 251. 
Muschel, L. H., AND Lowe, K. M. 1955. A new complement fixation test for syphilis. J. Lab. Clin. Med., 46, 147.

Stavitsky, A. B. 1954. Micromethods for the study of proteins and antibodies. I. Procedure and general applications of haemagglutination and haemagglutination-inhibition reactions with tannic acid and protein-treated red blood cells. J. Immun., 72, 360.

Wang, S. P., AND Grayston, J. T. 1964. Egg infectivity assay of trachoma virus. Proc. Soc. Exp. Biol. Med., 115, 587.

Zakay-Rones, Z., KATZENElson, E., AND LeVy, R. 1968. Haemagglutinin of trachoma agent. Israel J. Med. Sci., 4, 305. 